\title{
Continental-scale radar monitoring of the aerial movements of animals
}

\author{
Judy Shamoun-Baranes ${ }^{*}$, Jose A Alves ${ }^{2,3}$, Silke Bauer ${ }^{4}$, Adriaan M Dokter ${ }^{1,5}$, Ommo Hüppop $^{6}$, Jarmo Koistinen ${ }^{7}$, \\ Hidde Leijnse ${ }^{8}$, Felix Liechti ${ }^{4}$, Hans van Gasteren ${ }^{1,9}$ and Jason W Chapman ${ }^{10,11}$
}

\begin{abstract}
Billions of organisms travel through the air, influencing population dynamics, community interactions, ecosystem services and our lives in many different ways. Yet monitoring these movements are technically very challenging. During the last few decades, radars have increasingly been used to study the aerial movements of birds, bats and insects, yet research efforts have often been local and uncoordinated between research groups. However, a network of operational weather radars is continuously recording atmospheric conditions all over Europe and these hold enormous potential for coordinated, continental-scale studies of the aerial movements of animals.

The European Network for the Radar surveillance of Animal Movement (ENRAM) is a new e-COST research network aiming exactly at exploring this potential. The main objective of ENRAM is to merge expertise to utilize weather radars to monitor the aerial movement of animals across Europe for a broad range of stakeholders at an unprecedented scale and enable researchers to study the causes and consequences of movement. In this paper we describe the aims of ENRAM in more detail and the challenges researchers will address, provide an overview of aero-ecological studies using radar, and present some of the opportunities that a large sensor network can provide for movement ecology research.
\end{abstract}

Keywords: Aeroecology, Animal movement, Birds, Conservation, Europe, Insects, Migration, Radar, Research network, Weather

\section{Background}

Worldwide, billions of organisms of numerous taxa move through the air to disperse to new breeding areas, migrate to seasonally optimal habitats, search for resources and mates, avoid predators and find food, defend territories and much more, in short to meet their requirements for survival and reproduction [1-4]. Studying animal movement can be extremely challenging as organisms are often out of the line of sight of visual observers and technological tools are the only way to study their movements. Continuous miniaturization and technical innovation of devices have resulted in a revolution in tracking aerial movements of individuals; however, the relative mass of these devices is still a major constraint [5-7]. Thus, only a small fraction of species can be tracked with sensors attached to their bodies and

\footnotetext{
*Correspondence: shamoun@uva.nl

${ }^{1}$ Computational Geo-Ecology, IBED, University of Amsterdam, Amsterdam, the Netherlands

Full list of author information is available at the end of the article
}

within these species only a very small subsample of individuals are tracked, generally on the order of several to tens of individuals per study. Radar provides a complementary tool to study broad scale aerial movements, enabling researchers to study behavioural decisions of organisms, the timing and spatial distribution of their movements, their response to environmental conditions and, something not possible with individual tracking, quantify the temporal and spatial abundance of organisms in the air.

Radar has been used to study bird movements since the 1940's [8] and insect movements since the 1960's [9]. However, in recent years, radar ecology has experienced a renaissance with improved sensor technology, specialized radars designed for specific types of ecological research, improved data management and processing capacity, and algorithms for detecting and distinguishing between different biological targets [10-12]. In Europe, operational weather radars continuously monitor atmospheric conditions and are organized in a network 
(OPERA - Operational Program on the Exchange of Weather Radar Information) to facilitate data exchange and measurements at the continental scale [13]. One of the most promising developments for radar ecology in Europe has been the production of algorithms that successfully extract biological information from weather radars [11]. Until recently, radar ecology studies have been rather localized and scattered geographically across Europe. However, a multi-disciplinary group of researchers has taken action to change this situation. On 21 October 2013, a new four year e-COST (European Cooperation in Science and Technology) Action within the Domain Earth System Science and Environmental Management was launched: ENRAM, the European Network for the Radar surveillance of Animal Movement. In this paper, we briefly describe the aims and scopes of this new research network, highlight some of the recent research and applications related to animal movement using radar, and discuss some of the new opportunities we envisage through this network, which we hope will grow in the coming years.

\section{A new research network}

Operational weather radar data provides information about the spatial distribution, density, altitude, general speed and direction of organisms during flight. The radars are increasingly dual polarization systems which also provide information of the shape of the scattering objects. This novel information can greatly improve the ability to distinguish insects, birds, bats and hydrometeors (precipitation) in weather radar data [14]. The data are a unique and extensive source of information for ecological studies that contribute to a better understanding of animal movement. In several countries these data can be accessed for ecological research due to fruitful cooperation between meteorologists and biologists. However, there is the need to harmonize radar measurements and retrieval algorithms to achieve comparable data on a continental scale. The resulting standardized data is essential, in order to validate the results and to develop new algorithms for further differentiation of biological targets. Therefore, the main objective of ENRAM is to foster international and multi-disciplinary collaboration by establishing a European network of researchers with expertise in ecology, ornithology, entomology, meteorology, engineering, mathematics, visual analytics and computer sciences. Currently, 21 different countries are represented in the Action (Figure 1). The network will coordinate existing monitoring efforts, improve biological target identification and promote continental scale monitoring of aerial animal movement for the first time. In order to achieve these aims, numerous challenges will be addressed by the network in the coming years through the activities of four working groups (WG). While each WG has its own particular focus, addressing different technical and theoretical challenges related to radar research, they will work in close collaboration as their objectives are intertwined. Improving existing algorithms to extract biological information from weather radars, tailoring them to local conditions and applying these algorithms to operational weather radars across Europe will be addressed by WG 1. Improving our understanding of the properties of biological targets that are registered by radar is the main challenge that will be addressed by WG2. This will be done by conducting calibration experiments with multiple radar systems, namely specialized bird and entomological radars in conjunction with operational weather radar. The combination of different specialized sensors will provide essential information needed to improve the classification algorithms developed by WG 1. Most researchers are used to single radar study sites; a new challenge, to be addressed by WG 3 , is to effectively visualize and study large scale patterns across multiple radars, and to understand the processes that drive animal movements at synoptic scales. Finally, with information at hand about large scale animal movement patterns, WG 4 will integrate this information in animal movement research across multiple taxa.

\section{Recent insights from radar studies of animal movement}

By merging radar measurements and migration models, researchers have been able to explore some of the decision rules that govern movements of birds and insects and the impact that weather has on their flight paths. For example, huge numbers of birds or insects may travel great distances over the course of a night under suitable atmospheric conditions [15-17] and evidence is accumulating that even broad-fronted migratory movements are strongly spatially structured under influence of synoptic weather and geography [11,15,17]. Studies have also shown that during flight, birds and insects are typically not distributed randomly in the air but select specific altitudes with suitable environmental conditions [18-21]. Radar has also shed light on aspects of animal ecology that are very difficult to observe, such as the aerial roosting patterns of swifts [22,23], strategies for crossing ecological barriers such as the Sahara [24], the escape response of birds to large scale human disturbance such as fireworks [25], and mapping the distribution of wildfowl resting sites over large spatial extents [26].

Radar monitoring of animal movement and the use of radar data to develop movement forecasts serves a broad range of stakeholders. Aviation flight safety currently uses small and large scale radar for monitoring bird movements to reduce the risk of collisions between birds and aircraft, as well as using radar data to develop operational migration forecast models for the same purpose [27-29]. Radar is used to assess collision risks of birds 


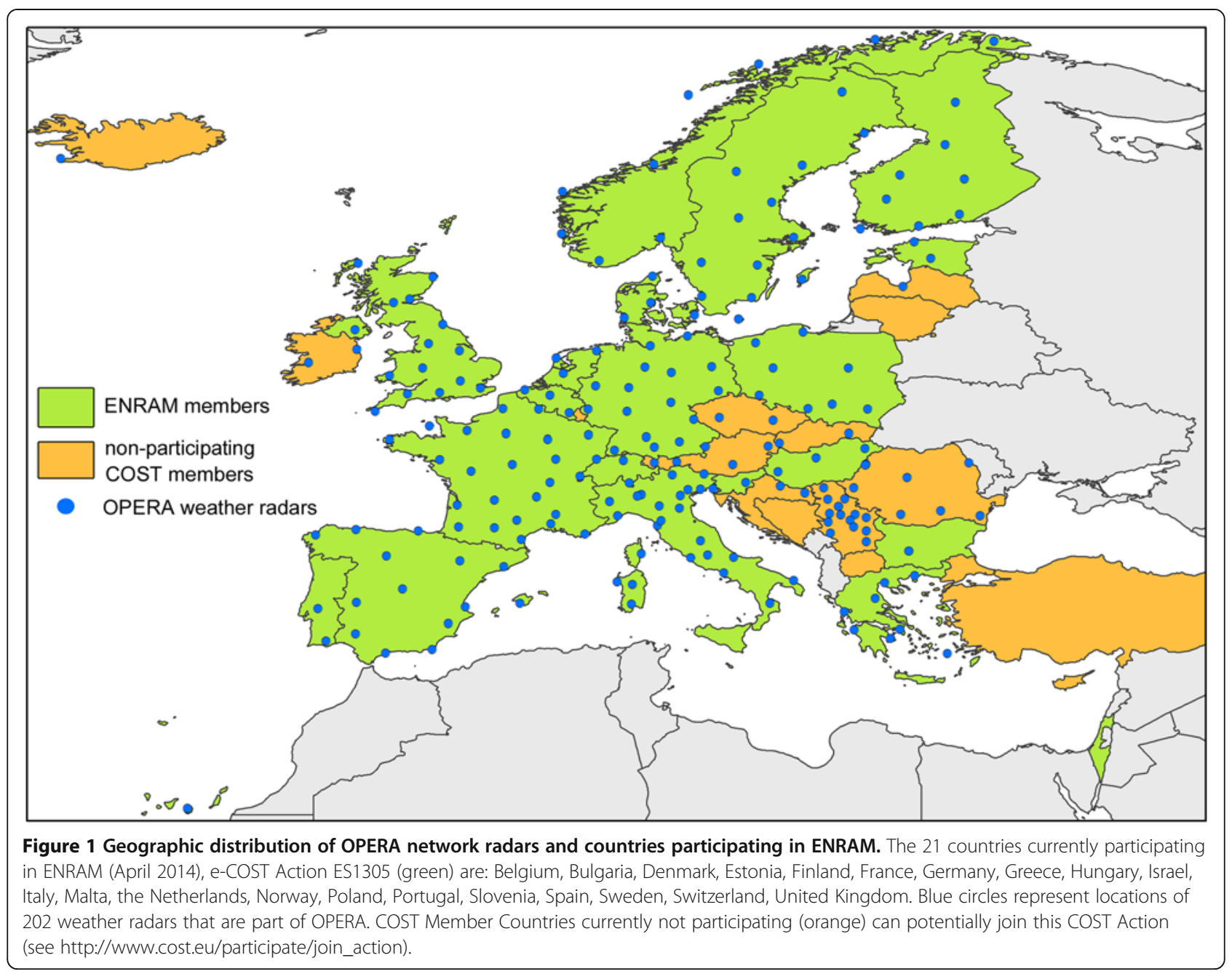

and bats with wind farms [30-33]. It can play an important role in monitoring and predicting pest invasions [34], predominantly for agriculture. Radar data can also inform conservation strategies, by monitoring population densities at known roost sites of birds and bats $[35,36]$, studying changes in phenology in specific species [37], and identifying important stopover locations [38] or flyways [39].

Weather radar products can be 'contaminated' with birds, bats or insects, reducing the quality of meteorological products, especially radial wind products [40] which are important for short-term weather prediction models. By improving the extraction of biological information from weather radar products the network will also improve the quality of operational meteorological products such as weather forecasts.

\section{New opportunities}

Working with a network of operational radars will provide a wide range of opportunities for fundamental research, as well as diverse applications and stakeholders.
Currently image mosaics calculated from volumetric weather radar data are already available for the OPERA network. ENRAM will actively work towards making such data and mosaics available for bird and insect migration studies. This will enable researchers to track movement in near-real time across borders, identify migratory flyways, quantify migration and set up longterm monitoring programs with infrastructure which is already largely in place. Although mosaics classified for biological targets are still not available, we provide an example of broad-front migration of birds on a night of peak migration in April 2013 as quantified on multiple weather radars in Belgium and the Netherlands (Figure 2). Data was processed from five different radars (De Bilt and Den Helder - the Netherlands, Jabbeke, Zaventem and Wideumont - Belgium) using a bird detection algorithm calibrated for passerine migration [11]. On this night, height integrated migration intensity was greatest at the inland sites (De Bilt, Zaventem and Wideumont), with over $100 \mathrm{birds} / \mathrm{km}^{2}$ at Wideumont, and at an altitude of approximately $2 \mathrm{~km}$ above ground 


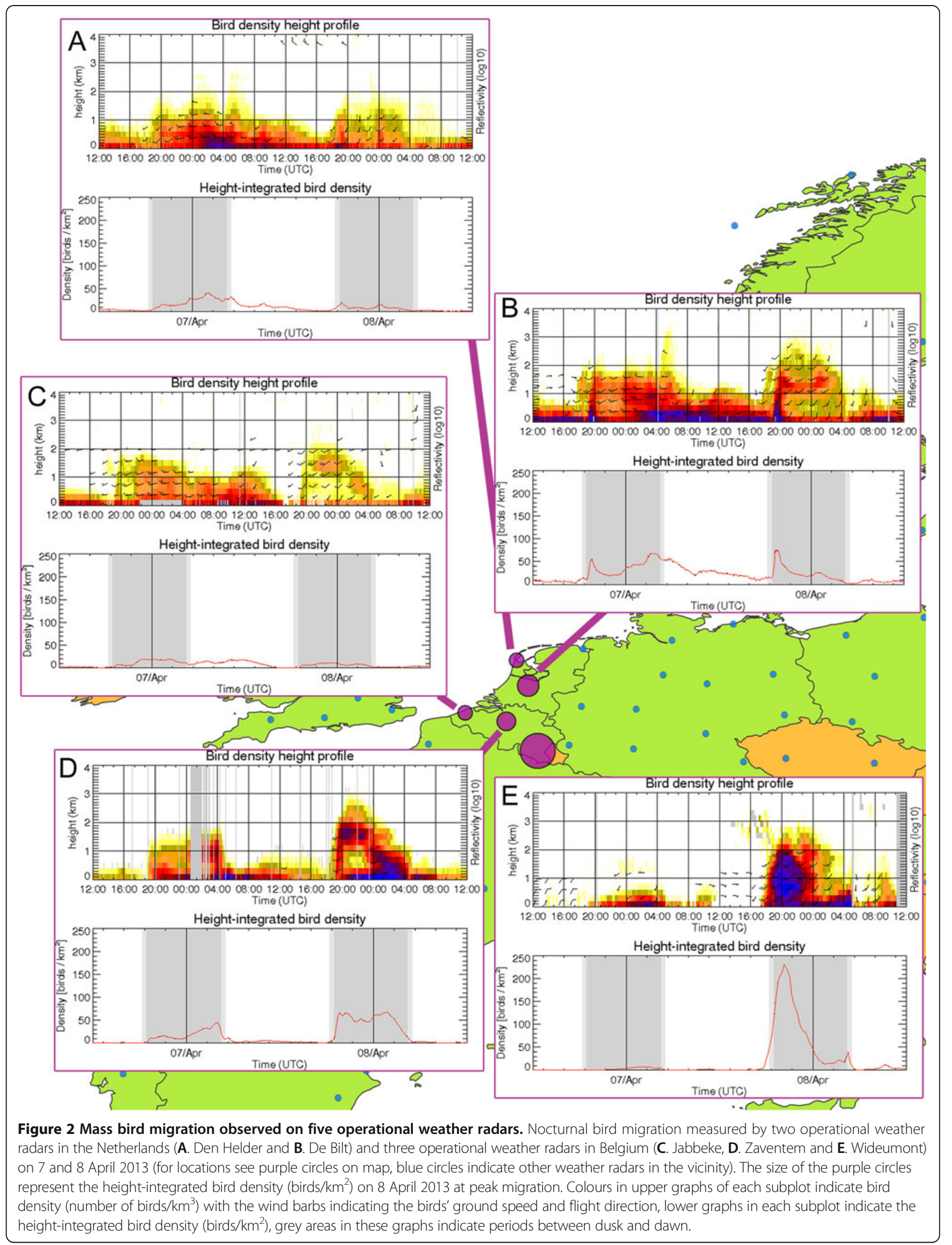


level. A migration layer is clearly visible at Jabbeke, De Bilt and Zaventem. Such layering events have been previously noted, predominantly in spring at single radar sites in temperate latitudes and can be ascribed to specific weather conditions, resulting in opposing winds at the surface and more supporting winds aloft [18].

By combining multiple radars covering a large spatial scale, researchers can begin remotely monitoring migration at the scale of synoptic weather systems. Gaps between radars can be filled with spatially explicit simulation models $[15,34,41]$ and mismatches between models and measurements can be used to improve our understanding of the responses of animals to weather and topography as well as study their orientation capacity in heterogeneous environmental conditions. ENRAM will work towards integrating information from complementary methods of measuring and modelling the distribution and movements of organisms, such as visual observations, individual tracking and simulation modelling. Such an integrated approach will enable researchers to follow populations of different species across the continent, quantify the movement of aerial biota at the continental scale, understand behavioural strategies of different taxa, the factors that drive emerging patterns in space and time at the population level, and the longer term consequences of the response of individuals to the environment, for individual fitness, population dynamics and ecosystem functioning [42-44].

\section{Conclusions}

We expect that operational weather radars will become an increasingly important tool for continuous real time monitoring of movement patterns of flying organisms. By bringing together an interdisciplinary group of researchers, ENRAM will facilitate new monitoring programs and research, resulting in ecological insights and improved weather forecasting. Researchers from any of the participating countries are welcome to join future activities of this research network, thus expanding the potential for multinational collaboration. We hope ENRAM quickly becomes a vibrant multidisciplinary community, and similar initiatives to develop an interdisciplinary network are underway in North America providing excellent opportunities for sharing expertise across continents [12,45]. The full Memorandum of Understanding and list of participating countries is publicly available on the e-COST website (http://www.cost.eu/ domains_actions/essem/Actions/ES1305) additional information about ENRAM is available at http://www. enram.eu.

\section{Abbreviations}

e-COST: European Cooperation in Science and Technology;

ENRAM: European Network for the Radar surveillance of Animal Movement;
OPERA: Operational Program on the Exchange of Weather Radar Information; WG: Working Groups.

\section{Competing interests}

The authors declare that they have no competing interests.

\section{Authors' contributions}

JSB designed, coordinated and wrote the manuscript; all authors contributed to the manuscript and designing the network. All authors read and approved the final manuscript.

\section{Acknowledgements}

The authors would like to thank everyone involved in the ENRAM network for discussions at earlier meetings held at the University of Amsterdam, Rothamsted Research and Institute of Avian Research, preceding the e-COST Action. The authors thank the Royal Meteorological Institute of Belgium for usage of the Belgian weather radar data and Robert van Versendaal, KNMI for assistance with Figure 2. We thank Phil Chilson and one anonymous reviewer for their feedback on an earlier version of this manuscript. The authors acknowledge the support provided by COST - European Cooperation in Science and Technology for the realization of this paper. The contents of this paper are the authors' responsibility and neither COST nor any person acting on its behalf is responsible for the use which might be made of the information contained in it. Rothamsted Research is a national institute of bioscience strategically funded by the UK Biotechnology and Biological Sciences Research Council (BBSRC).

\section{Author details}

${ }^{1}$ Computational Geo-Ecology, IBED, University of Amsterdam, Amsterdam, the Netherlands. ${ }^{2}$ CESAM, University of Aveiro, Campus de Santiago, 3810-193 Aveiro, Portugal. ${ }^{3}$ South Iceland Research Centre, University of Iceland, IS-800 Selfoss, Iceland. ${ }^{4}$ Swiss Ornithological Institute, Sempach, Switzerland. ${ }^{5}$ Centre for Avian Migration and Demography and Department of Animal Ecology, Netherlands Institute of Ecology (NIOO-KNAW), Wageningen, the Netherlands. ${ }^{6}$ Institute of Avian Research "Vogelwarte Helgoland", Wilhelmshaven, Germany. ${ }^{7}$ Finnish Meteorological Institute, Helsinki, Finland. ${ }^{8}$ Royal Netherlands Meteorological Institute (KNMI), De Bilt, the Netherlands. ${ }^{9}$ Air Force Command, Royal Netherlands Air Force, Utrecht, the Netherlands. ${ }^{10}$ Department of AgroEcology, Rothamsted Research, Harpenden, UK. ${ }^{11}$ Environment and Sustainability Institute, University of Exeter, Cornwall, UK.

Received: 19 February 2014 Accepted: 26 March 2014

Published: 20 May 2014

\section{References}

1. Holland RA, Wikelski M, Wilcove DS: How and why do insects migrate? Science 2006, 313:794-796.

2. Hahn S, Bauer S, Liechti F: The natural link between Europe and Africa - 2.1 billion birds on migration. Oikos 2009, 118:624-626.

3. Boyles JG, Cryan PM, McCracken GF, Kunz TH: Economic Importance of Bats in Agriculture. Science 2011, 332:41-42.

4. Chapman JW, Bell JR, Burgin LE, Reynolds DR, Pettersson LB, Hill JK, Bonsall MB, Thomas JA: Seasonal migration to high latitudes results in major reproductive benefits in an insect. Proc Natl Acad Sci 2012, 109:14924-14929.

5. Robinson WD, Bowlin MS, Bisson I, Shamoun-Baranes J, Thorup K, Diehl RH, Kunz TH, Mabey S, Winkler DW: Integrating concepts and technologies to advance the study of bird migration. Front Ecol Environ 2010, 8:354-361.

6. Bridge ES, Thorup K, Bowlin MS, Chilson PB, Diehl RH, Fléron RW, Hartl P, Roland K, Kelly JF, Robinson WD, Wikelski M: Technology on the move: recent and forthcoming innovations for tracking migratory birds. Bioscience 2011, 61:689-698.

7. Kissling WD, Pattemore DE, Hagen M: Challenges and prospects in the telemetry of insects. Biol Rev 2013. n/a-n/a. doi:10.1111/brv.12065.

8. Lack D, Varley GC: Detection of birds by radar. Nature 1945, 156:446-446.

9. Chapman JW, Drake VA, Reynolds DR: Recent insights from radar studies of insect flight. Annu Rev Entomol 2011, 56:337-356.

10. Zaugg S, Saporta G, Loon E, Schmaljohann H, Liechti F: Automatic identification of bird targets with radar via patterns produced by wing flapping. J R Soc Interface 2008, 5:1041-1053. 
11. Dokter AM, Liechti F, Stark H, Delobbe L, Tabary P, Holleman I: Bird migration flight altitudes studied by a network of operational weather radars. J $R$ Soc Interface 2011, 8:30-43.

12. Chilson PB, Frick WF, Kelly JF, Howard KW, Larkin RP, Diehl RH, Westbrook JK, Kelly TA, Kunz TH: Partly cloudy with a chance of migration: weather, radars, and aeroecology. Bull Am Meteorol Soc 2012, 93:669-686.

13. Huuskonen A, Saltikoff E, Holleman I: The operational weather radar network in Europe. Bull Am Meteorol Soc 2013. doi:http://dx.doi.org/ 10.1175/BAMS-D-12-00216.1.

14. Zrnic DS, Ryzhkov AV: Observations of insects and birds with a polarimetric radar. IEEE Trans Geoscience Remote Sensing 1998, 36:661-668.

15. Shamoun-Baranes J, van Gasteren H: Atmospheric conditions facilitate mass migration events across the North Sea. Anim Behav 2011, 81:691-704.

16. Chapman JW, Nesbit RL, Burgin LE, Reynolds DR, Smith AD, Middleton DR, Hill JK: Flight orientation behaviors promote optimal migration trajectories in high-flying insects. Science 2010, 327:682-685.

17. Nieminen $M$, Leskinen $M$, Helenius J: Doppler radar detection of exceptional mass-migration of aphids into Finland. Int J Biometeorol 2000, 44:172-181.

18. Dokter AM, Shamoun-Baranes J, Kemp MU, Tijm S, Holleman I: High altitude bird migration at temperate latitudes: a synoptic perspective on wind assistance. PLOS ONE 2013, 8:e52300.

19. Shamoun-Baranes J, van Loon E, van Gasteren H, van Belle J, Bouten W, Buurma $\mathrm{L}$ : A comparative analysis of the influence of weather on the flight altitudes of birds. Bull Am Meteorol Soc 2006, 87:47-61.

20. Schmaljohann H, Liechti F, Bruderer B: Trans-Sahara migrants select flight altitudes to minimize energy costs rather than water loss. Behav Ecol Sociobiol 2009, 63:1609-1619.

21. Alerstam T, Chapman JW, Bäckman J, Smith AD, Karlsson H, Nilsson C, Reynolds DR, Klaassen RHG, Hill JK: Convergent patterns of long-distance nocturnal migration in noctuid moths and passerine birds. Proc $R$ Soc $B$ Biol Sci 2011, 278:3074-3080.

22. Backman J, Alerstam T: Harmonic oscillatory orientation relative to the wind in nocturnal roosting flights of the swift Apus apus. J Exp Biol 2002, 205:905-910.

23. Dokter AM, Åkesson S, Beekhuis H, Bouten W, Buurma L, van Gasteren H, Holleman I: Twilight ascents by common swifts, Apus apus, at dawn and dusk: acquisition of orientation cues? Anim Behav 2013, 85:545-552.

24. Schmaljohann $H$, Liechti $F$, Bruderer B: Songbird migration across the Sahara: the Non-stop hypothesis rejected! Proc R Soc B Biol Sci 2007, 274:735-739.

25. Shamoun-Baranes J, Dokter AM, van Gasteren H, van Loon EE, Leijnse H, Bouten W: Birds flee en mass from New Year's Eve fireworks. Behav Ecol 2011, 22:1173-1177

26. Buler JJ, Randall LA, Fleskes JP, Barrow WC Jr, Bogart T, Kluver D: Mapping wintering waterfowl distributions using weather surveillance radar. PLOS ONE 2012, 7:e41571.

27. Ginati A, Coppola D, Garofalo G, Shamoun-Baranes J, Bouten W, van Gasteren H, Dekker A, Sorbi S: FlySafe: an early warning system to reduce risk of bird strikes. Eur Space Agency Bull 2010, 144:46-55.

28. Shamoun-Baranes J, Bouten W, Buurma L, DeFusco R, Dekker A, Sierdsema $H$, Sluiter F, van Belle J, van Gasteren H, van Loon E: Avian information systems: developing web-based bird avoidance models. Ecol Soc 2008 13:38

29. van Belle J, Shamoun-Baranes J, van Loon E, Bouten W: An operational model predicting autumn bird migration intensities for flight safety. J Appl Ecol 2007, 44:864-874.

30. Desholm M, Fox AD, Beasley PDL, Kahlert J: Remote techniques for counting and estimating the number of bird-wind turbine collisions at sea: a review. Ibis 2006, 148:76-89.

31. Gauthreaux SA, Belser CG: Radar ornithology and biological conservation Auk 2003, 120:266-277.

32. Huppop O, Dierschke J, Exo K-M, Fredrich E, Hill R: Bird migration studies and potential collision risk with offshore wind turbines. Ibis 2006, 148:90-109.

33. Ahlén I, BaagØe HJ, Bach L: Behavior of Scandinavian bats during migration and foraging at Sea. J Mammal 2009, 90:1318-1323.

34. Leskinen M, Markkula I, Koistinen J, Pylkkö P, Ooperi S, Siljamo P, Ojanen H, Raiskio S, Tiilikkala K: Pest insect immigration warning by an atmospheric dispersion model, weather radars and traps. J Appl Entomol 2011, 135:55-67.
35. Horn JW, Kunz TH: Analyzing NEXRAD doppler radar images to assess nightly dispersal patterns and population trends in Brazilian free-tailed bats (Tadarida brasiliensis). Int Comp Biol 2008, 48:24-39.

36. Russell KR, Gauthreaux SA Jr: Use of weather radar to characterize movements of roosting purple martins. Wildl Soc Bull 1998, 26:5-16.

37. Kelly JF, Shipley JR, Chilson PB, Howard KW, Frick WF, Kunz TH: Quantifying animal phenology in the aerosphere at a continental scale using NEXRAD weather radars. Ecosphere 2012, 3:art16.

38. Bonter DN, Gauthreaux SA Jr, Donovan TM: Characteristics of important stopover locations for migrating birds: remote sensing with radar in the Great Lakes Basin. Conserv Biol 2009, 23:440-448.

39. Leshem Y, Yom-Tov Y: Routes of migrating soaring birds. Ibis 1998 $140: 41-52$.

40. Holleman I, van Gasteren H, Bouten W: Quality assessment of weather radar wind profiles during bird migration. J Atmos Ocean Technol 2008, 25:2188-2198

41. McLaren JD, Shamoun-Baranes J, Bouten W: Wind selectivity and partial compensation for wind drift among nocturnally migrating passerines. Behav Ecol 2012, 23:1089-1101.

42. Shamoun-Baranes J, Bouten W, van Loon EE: Integrating meteorology into research on migration. Int Comp Biol 2010, 50:280-292.

43. Bowlin MS, Bisson I-A, Shamoun-Baranes J, Reichard JD, Sapir N, Marra PP, Kunz TH, Wilcove DS, Hedenstrom A, Guglielmo CG, Åkesson S, Ramenofsky M, Wikelski M: Grand challenges in migration biology. Int Comp Biol 2010 50:261-279

44. Bauer S, Hoye BJ: Migratory Animals Couple Biodiversity and Ecosystem Functioning Worldwide. Science 2014, 344:1242552.

45. Chilson PB, Bridge E, Frick WF, Chapman JW, Kelly JF: Radar aeroecology: exploring the movements of aerial fauna through radio-wave remote sensing. Biol Lett 2012, 8:698-701.

doi:10.1186/2051-3933-2-9

Cite this article as: Shamoun-Baranes et al:: Continental-scale radar monitoring of the aerial movements of animals. Movement Ecology 2014 2:9.

\section{Submit your next manuscript to BioMed Central and take full advantage of:}

- Convenient online submission

- Thorough peer review

- No space constraints or color figure charges

- Immediate publication on acceptance

- Inclusion in PubMed, CAS, Scopus and Google Scholar

- Research which is freely available for redistribution 